\title{
Three-Dimensional Bioconvection Nanofluid Flow from a Bi-Axial Stretching Sheet with Anisotropic Slip
}

(Aliran Nanobendalir Bioperolakan Tiga Matra daripada Lembaran Regangan Dua Paksi dengan Gelincir Anisotropi)

\author{
Nur Ardiana Amirsom, M.J. Uddin, Md. FAisal Md BASIR*, A.I.M Ismail, O. ANWAR BÉG \& Ali Kadir
}

\begin{abstract}
A theoretical study is presented for three-dimensional flow of bioconvection nanofluids containing gyrotactic microorganisms over a bi-axial stretching sheet. The effects of anisotropic slip, thermal jump and mass slip are considered in the mathematical model. Suitable similarity transformations are used to reduce the partial differential equation system into a nonlinear ordinary differential system. The transformed nonlinear ordinary differential equations with appropriate transformed boundary conditions are solved numerically with the bvp4c procedure in the symbolic software, MATLAB. The mathematical computations showed that an increase in Brownian motion parameter corresponds to a stronger thermophoretic force which encourages transport of nanoparticles from the hot bi-axial sheet to the quiescent fluid. This increases the nanoparticle volume fraction boundary layer. Fluid temperature and thermal boundary layer thickness are decreased with increasing stretching rate ratio of the bi-axial sheet. The present simulation is of relevance in the fabrication of bio-nanomaterials and thermally-enhanced media for bio-inspired fuel cells.
\end{abstract}

Keywords: Anisotropic slip; bioconvection; mass slip; microorganisms; nanofluids, thermal slip

\section{ABSTRAK}

Satu kajian secara teori dibentangkan untuk aliran tiga matra nanobendalir bioperolakan yang mengandungi mikroorganisma girotaktik yang melalui lembaran regangan dua-paksi. Kesan gelincir anisotropi, haba dan jisim telah dipertimbangkan dalam model matematik. Transformasi persamaan yang sesuai digunakan untuk menurunkan sistem persamaan pembezaan separa ke dalam sistem pembezaan biasa bukan linear. Persamaan pembezaan biasa bukan linear dengan syarat sempadan diselesaikan secara berangka dengan prosedur bvp4c dalam perisian simbolik, MATLAB. Pengiraan matematik telah mendedahkan bahawa peningkatan dalam parameter gerakan Brownian sepadan dengan daya termoforetik yang lebih kuat yang menggalakkan pengangkutan nanopartikel daripada lembaran dua-paksi panas ke cecair statik. Hal ini meningkatkan lapisan sempadan pecahan isi padu nanopartikel. Suhu cecair dan ketebalan lapisan sempadan haba berkurangan dengan nisbah kadar regangan yang semakin meningkat pada lembaran dua paksi. Simulasi terkini adalah berkaitan dalam pembuatan bio-bahan nano dan peningkatan media haba untuk sel sel bahan api yang diilhami bio.

Kata kunci: Gelincir anistropi; gelincir haba; gelincir jisim; mikroorganisma; nanobendalir; bioperolakan

\section{INTRODUCTION}

Heat transfer enhancement has and continues to draw significant attention in many engineering and industrial problems. Various techniques have been implemented to improve the heat transfer efficiency. There include modifications in flow geometry, increasing thermal conductivity of working fluids, incorporating radiative heat transfer or heat source or by changing boundary conditions (Webb \& Kim 2004). Several studies have reported that heat transfer can be strongly enhanced by suspending higher thermal conductivity micro/nano solid particles in the base fluid. Although the high density and large size of the solid particles and associated settling of the solid particles may cause clogging problems in microsystems, these issues can be resolved by using lower concentrations of very small sized particles which are referred as nanofluids. Nanofluids were introduced by Choi and Eastman (1995) and constitute fluids which contain a dispersion of nanoparticles having diameters ranging between 1-100 $\mathrm{nm}$ in base fluid (water, lubricants, ethylene glycol, polymer solutions) to ensure heat transfer enhancement. Nanoparticles are generally made up of metal, metal oxides, carbides, nitrides or other non-metallic materials. The motion of nanoparticles within nanofluids is generally attributed principally to Brownian motion and thermophoresis, although other effects (micro-convection $\&$ ballistic collisions) may contribute. Buongiorno (2006) introduced a popular convective transport model for nanofluids where Brownian and thermophoresis diffusion are the dominant effects. Michaelides (2015) studied Brownian movement and thermophoresis of nanoparticles in liquids and observed that thermophoretic 
coefficient depends strongly on the size (radius) of the nanoparticles and weakly on the particle-to-fluid density ratio. Some demonstrated applications of nanofluids include automotive coolant, nanomaterial processing, microbial fuel cell technology, polymer coating, rocket fuels and microfluid delivery devices (Saidur et al. 2011). Chamkha and Aly (2010) illustrates MHD free convective flow of a nanofluid past a vertical plate in the presence of heat generation/absorption. Chamkha et al. (2012b) studied radiation effects on mixed convection over a wedge embedded in a porous medium filled with a nanofluid. In another paper Chamkha et al. (2012a) illustrate radiative effects on boundary-layer flow of a nanofluid on a continuously moving or fixed permeable surface.

The combined interaction between nanofluids and bioconvection patterns has also been shown to be of great potential in improving microfluidic devices (bacteriapowered micro mixers). Nanoparticles enhance thermal performance in bioconvection flows and micro-organisms simultaneously increase the stability of nanofluids. Bioconvection has been defined as a microscopic convection in a fluid by up-swimming microorganisms which are heavier than water. These self-propelled microorganisms enhance the density of the base fluid due to swimming directions which are controlled by different taxes (light, chemical reactions, gravity, magnetic fields \& torque) and manifesting in bioconvection. The presence of water (base fluid) in nanofluids is very important to keep the microorganism alive. Bioconvection can be applied in bio-microsystems (enzyme biosensors) and biotechnology owing to mass transport enhancement and mixing, which are significant issues in many micro-systems (Sokolov et al. 2009; Tsai et al. 2009). Kuznetsov and Avramenko (2004) first studied the bioconvection of gyrotatic microorganism that contain solid small particles. Kuznetsov (2012) later proposed the theory of suspension of oxytatic microorganism and nanoparticles, in which swimming velocity of oxytatic microorganisms is determined by the oxygen concentration gradient. Khan et al. (2013) and Uddin et al. (2013) investigated the free convection flow of non-Newtonian nanofluids in a porous medium containing gyrotatic microorganisms. Xu and Pop (2012) studied fully developed mixed convection channel flows of nanofluids containing gyrotatic microorganisms. Siddiqa et al. (2016) considered bioconvection flow from an undulating surface geometry (cone) with heat and mass transfer of nanofluids containing gyrotatic microorganisms. Amirsom et al. (2016) have studied the stagnation point bioconvection nanofluid flow with variable transport properties. Very recently, the effect of variable thermal properties of nanofluids on bioconvection along a uniformly heated vertical cone was investigated by Begum et al. (2017).

In many real-world applications, slip phenomena arise at the interface between solid boundaries and fluids. Many studies have considered slip boundary conditions which may be hydrodynamic, thermal or of other types. Tripathi et al. (2014) considered momentum slip effects on peristaltic propulsion of viscoelastic fluids in deformable tubes.
Prasad et al. (2013) examined thermal and velocity slip effects on viscoplastic heat transfer from a curved body. Rao et al. (2016) investigated thermal jump and momentum slip effects in rheological porous media transport. Akbar et al. (2016) considered momentum and thermal slip effects on ciliated channel magnetic physiological flow. Maqbool et al. (2016) investigated hydrodynamic wall slip effects on several rotating and oscillatory hydromagnetic nonNewtonian porous media channel flows. Turkyilmazoglu (2015) studied hydrodynamic and thermal slip effects on transport in a wedge nozzle (converging channel), deriving unique, double, or triple solutions and showing that these are strongly dependent on the slip effects. Slip effects in nanofluid dynamics have also received considerable attention in recent years. They have been studied in bioconvection nanofluid expanding/contracting wall channel flows (Bég et al. 2017), transient micropolar nanofluids bioconvection from stretching sheets (Abdul Latiff et al. 2016), radiative-convective nanofluid flows from extending/contracting sheets (Uddin et al. 2015) and time-dependent bioconvection nanofluid transport from expanding curved bodies (Md Basir et al. 2016).

The mentioned studies have all considered isotropic slip. Anisotropic slip is directionally dependent and can arise in lubrication problems with partially wetted bearing surfaces, polymer manufacturing, geometrically striated surfaces and superhydrophobic boundaries (Chen et al. 2013). Slip in different directions has been shown to exert a significant influence on velocity, temperature and also mass transfer characteristics in such systems. Rashad (2017) has investigated the influence of anisotropic slip on unsteady ferrofluid heat transfer with thermal radiation from an inclined stretching sheet. Wang (2013) has studied anisotropic slip effects on an axisymmetric stagnation flow of a Newtonian fluid using asymptotic analysis for large slip and numerical integration. Uddin et al. (2016) obtained numerical solutions for anisotropic momentum and thermal slip effects on three-dimensional stagnation point nanofluid bio-convection flow. Jao et al. (2016) have developed a robust model for anisotropic hydrodynamic slip in rheological flows. Anisotropic slip bioconvection nanofluid flows have been addressed by Raees et al. (2016) and Uddin et al. (2016). Recently, several nanofluid flows past a surface (movable/non-movable) are inspected under various physical constraints (for fluid flow) (Akbarzadeh et al. 2018; Alamri et al. 2019; Aziz et al. 2018; Hassan et al. 2018a, 2018b; Hussain et al. 2018; Jamaludin et al. 2018; Mahat et al. 2018; Rashidi et al. 2018; Shehzad et al. 2018; Zeeshan et al. 2018).

The present study investigates the effects of anisotropic slip, thermal jump and mass slip on boundary layer bioconvection flow of nanofluids containing motile microorganisms over a bi-axial stretching sheet. Most of studies concerning nanofluids and bioconvection on stretching/contracting surfaces have been confined to one-dimensional stretching or shrinking. In certain fabrication processes of nanomaterials, both shrinking, and contraction may be achieved simultaneously in mutually 
orthogonal directions, a scenario known as bi-axial stretching/contracting. Several studies have examined fluid dynamics of such systems. Wang (2011) presented one of the earliest analytical solutions for heat transfer in a fluid film sprayed on a biaxial shrinking/stretching sheet, observing that for certain rates of shrinking it is possible for the film to sustain a free surface of constant depth. Wang (2015) further studied numerically the uniform flow of a Newtonian fluid from a bi-axial stretching surface, noting that the shear stress is enhanced with lateral stretching. Liu and Andersson (2008) computed solutions for the thermal convection in steady three-dimensional viscous flow driven by the bidirectional stretching of an elastic surface, showing that boundary layer thickness is decreased when there is a reduction in sheet temperature or heat transfer rate is increased in one or both lateral directions. Mustafa et al. (2015) studied the influence of radiative flux on three-dimensional flow and heat transfer from a bi-axial exponentially stretching sheet. In the context of nanofluids, Khan et al. (2015) investigated numerically the three-dimensional flow of nanofluid over a bi-directional stretching sheet using the Keller-box method. To the best of authors' knowledge, thus far the bioconvection nanofluid flow from a biaxially stretching/contracting sheet has not been considered in the literature. The current work extends the study of Khan et al. (2015) to consider bioconvection and anisotropic slip and Liu et al. (2013) to consider anisotropic slip, nanofluids and bioconvection (by incorporating the combined effects of Brownian motion and thermophoresis). Numerical solutions are presented. The study is relevant to bio-nano-materials processing. Slip effects are relevant to real flows with bio-nano-polymers (non-adhesion). Bioconvection is relevant to doping fuel cell media with microscopic swimmers to influence heat and mass transfer rates. Nanoparticles are used for enhancing thermal properties. Together these effects are required to simulate properly the manufacturing of bionano-materials via bi-axial stretching.

\section{MATHEMATICAL MODEL}

We consider three-dimensional steady flow of incompressible viscous Newtonian nanofluids containing motile micro-organisms from a moving bi-axial stretching sheet with anisotropic slip, thermal jump, mass slip and microorganism slip effects. The physical regime is illustrated in Figure 1. The sheet at $\bar{z}=0$ is stretched in the $\bar{x}$ and $\bar{y}$ directions with velocities $\bar{u}_{w}(\bar{x})=a(\bar{x}+\bar{y})^{n}+N_{1}(\bar{x}, \bar{y})\left(\frac{\partial \bar{u}}{\partial \bar{z}}\right)$ and $\bar{v}_{w}(\bar{y})=b(\bar{x}+\bar{y})^{n}+N_{2}(\bar{x}, \bar{y})\left(\frac{\partial \bar{v}}{\partial \bar{z}}\right)$, respectively, where $a, b, n>0$ denote constants. The boundary layer equations for three-dimensional bioconvection flow of viscous nanofluids are (Khan et al. 2015a):

$$
\frac{\partial \bar{u}}{\partial \bar{x}}+\frac{\partial \bar{v}}{\partial \bar{y}}+\frac{\partial \bar{w}}{\partial \bar{z}}=0
$$

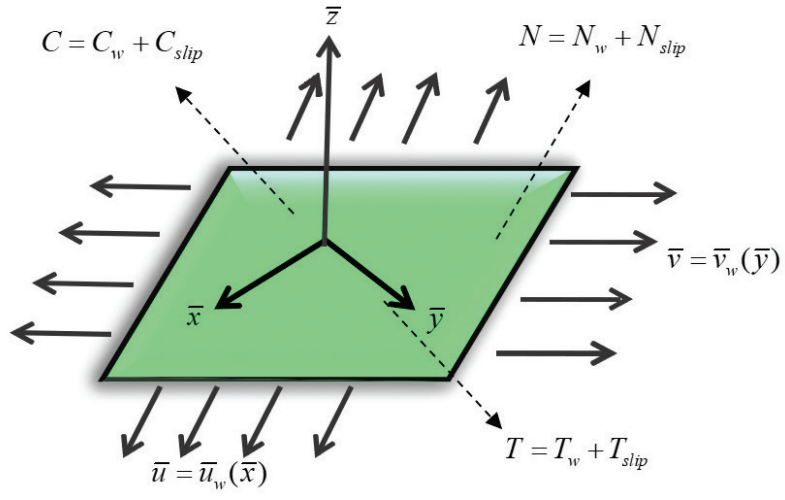

FIGURE 1. Physical configuration and coordinate system (Khan et al. 2015a)

$$
\begin{aligned}
& \bar{u} \frac{\partial \bar{u}}{\partial \bar{x}}+\bar{v} \frac{\partial \bar{u}}{\partial \bar{y}}+\bar{w} \frac{\partial \bar{u}}{\partial \bar{z}}=v_{f} \frac{\partial^{2} \bar{u}}{\partial \bar{z}^{2}}, \\
& \bar{u} \frac{\partial \bar{v}}{\partial \bar{x}}+\bar{v} \frac{\partial \bar{v}}{\partial \bar{y}}+\bar{w} \frac{\partial \bar{v}}{\partial \bar{z}}=v_{f} \frac{\partial^{2} \bar{v}}{\partial \bar{z}^{2}}, \\
& \bar{u} \frac{\partial T}{\partial \bar{x}}+\bar{v} \frac{\partial T}{\partial \bar{y}}+\bar{w} \frac{\partial T}{\partial \bar{z}}=\alpha \frac{\partial^{2} T}{\partial z^{2}}+\tau\left[D_{B} \frac{\partial C}{\partial \bar{z}} \frac{\partial T}{\partial \bar{z}}+\frac{D_{T}}{T_{\infty}}\left(\frac{\partial T}{\partial \bar{z}}\right)^{2}\right], \\
& \bar{u} \frac{\partial C}{\partial \bar{x}}+\bar{v} \frac{\partial C}{\partial \bar{y}}+\bar{w} \frac{\partial C}{\partial \bar{z}}=D_{B} \frac{\partial^{2} C}{\partial \bar{z}^{2}}+\frac{D_{T}}{T_{\infty}} \frac{\partial^{2} T}{\partial \bar{z}^{2}}, \\
& \bar{u} \frac{\partial N}{\partial \bar{x}}+\bar{v} \frac{\partial N}{\partial \bar{y}}+\bar{w} \frac{\partial N}{\partial \bar{z}}+\frac{\tilde{b} W_{c}}{C_{w}-C_{\infty}}\left[\frac{\partial}{\partial \bar{z}}\left(N \frac{\partial C}{\partial \bar{z}}\right)\right]=D_{N} \frac{\partial N}{\partial \bar{z}} .
\end{aligned}
$$

Modifying from Khan et al. (2015(a)), the imposed boundary conditions at the sheet surface (wall) and in the free stream are:

$$
\begin{aligned}
& \bar{u}=\bar{u}_{w}(\bar{x})=a(\bar{x}+\bar{y})^{n}+N_{1}(\bar{x}, \bar{y})\left(\frac{\partial \bar{u}}{\partial \bar{z}}\right), \\
& \bar{v}=\bar{v}_{w}(\bar{y})=b(\bar{x}+\bar{y})^{n}+N_{2}(\bar{x}, \bar{y})\left(\frac{\partial \bar{v}}{\partial \bar{z}}\right), \\
& \bar{w}=0, \quad T=T_{w}+D_{1}(\bar{x}, \bar{y})\left(\frac{\partial T}{\partial \bar{z}}\right), \\
& C=C_{w}+E_{1}(\bar{x}, \bar{y})\left(\frac{\partial C}{\partial \bar{z}}\right), \\
& N=N_{w}+F_{1}(\bar{x}, \bar{y})\left(\frac{\partial N}{\partial \bar{z}}\right) \\
& \bar{u} \rightarrow 0, \quad \bar{v} \rightarrow 0, \quad T \rightarrow T_{\infty}, \quad C \rightarrow C_{\infty}, \quad N \rightarrow 0 \quad \text { at } \bar{z}=0,
\end{aligned}
$$

where $\bar{u}, \bar{v}$ and $\bar{w}$ are the velocity components along the axes, respectively; $v_{f}$ is the kinematic viscosity of the fluid; $\tilde{b}$ is the chemotaxis constant; $W_{c}$ is the maximum cell swimming speed; $D_{B}$ is Brownian diffusion 
coefficient; $D_{T}$ is thermophoretic diffusion coefficient; $D_{N}$ is microorganisms diffusion coefficient; $\alpha$ is thermal diffusivity; $N_{1}(\bar{x}, \bar{y})=\left(N_{1}\right)_{0}(\bar{x}+\bar{y})^{\frac{1-n}{2}}$ is velocity slip factor at $\bar{x}$ direction; $N_{2}(\bar{x}, \bar{y})=\left(N_{2}\right)_{0}(\bar{x}+\bar{y})^{\frac{1-n}{2}}$ is velocity slip factor at $\bar{y}$ direction $D_{1}(\bar{x}, \bar{y})=\left(D_{1}\right)_{0}(\bar{x}+\bar{y})^{\frac{1-n}{2}}$ is thermal slip factor; $E_{1}(\bar{x}, \bar{y})=\left(E_{1}\right)_{0}(\bar{x}+\bar{y})^{\frac{1-n}{2}}$ is mass slip factor; and $F_{1}(\bar{x}, \bar{y})=\left(F_{1}\right)_{0}(\bar{x}+\bar{y})^{\frac{1-n}{2}}$ is microorganism slip factor.

Introducing the following set of similarity transformations (Khan et al. 2015a):

$$
\begin{aligned}
& \eta=(\bar{x}+\bar{y})^{\frac{n-1}{2}} \sqrt{\frac{a}{v_{f}}} \bar{z}, \quad \bar{u}=a(\bar{x}+\bar{y})^{n} f^{\prime}(\eta), \quad \bar{v}=a(\bar{x}+\bar{y})^{n} g^{\prime}(\eta), \\
& \bar{w}=-\sqrt{a v_{f}}(\bar{x}+\bar{y})^{\frac{n-1}{2}}\left(\frac{n+1}{2}(f+g)+\frac{n-1}{2} \eta\left(f^{\prime}+g^{\prime}\right)\right), \\
& \theta(\eta)=\frac{T-T_{\infty}}{T_{w}-T_{\infty}}, \quad \phi(\eta)=\frac{C-C_{\infty}}{C_{w}-C_{\infty}}, \quad \chi(\eta)=\frac{N}{N_{w}} .
\end{aligned}
$$

Here all parameters are defined in the nomenclature. Using (8), the continuity (1) is identically satisfied and governing Equations (2) - (6) are transformed into a system ordinary differential equations (ODEs):

$$
\begin{aligned}
& f^{\prime \prime \prime}+\frac{n+1}{2}(f+g) f^{\prime \prime}-n\left(f^{\prime}+g^{\prime}\right) f^{\prime}=0, \\
& g^{\prime \prime \prime}+\frac{n+1}{2}(f+g) g^{\prime \prime}-n\left(f^{\prime}+g^{\prime}\right) g^{\prime}=0, \\
& \theta^{\prime \prime}+\frac{n+1}{2} \operatorname{Pr}(f+g) \theta^{\prime}+N b \theta^{\prime} \phi^{\prime}+N t \theta^{\prime 2}=0, \\
& \phi^{\prime \prime}+\frac{n+1}{2} S c(f+g) \phi^{\prime}+\frac{N t}{N b} \theta^{\prime \prime}=0, \\
& \chi^{\prime \prime}-P e\left[\chi \phi^{\prime \prime}+\phi^{\prime} \chi^{\prime}\right]+\frac{n+1}{2} L b(f+g) \chi^{\prime}=0,
\end{aligned}
$$

The transformed boundary conditions emerge as:

$$
\begin{aligned}
& f^{\prime}(0)=1+p f^{\prime \prime}(0), \quad g^{\prime}(0)=\lambda+q g^{\prime \prime}(0), \quad f(0)=g(0)=0, \\
& \theta(0)=1+r \theta^{\prime}(0), \quad \phi(0)=1+s \phi^{\prime}(0), \quad \chi(0)=1+k \chi^{\prime}(0) \quad \text { at } \eta=0, \\
& f^{\prime}(\infty) \rightarrow 0, g^{\prime}(\infty) \rightarrow 0, \theta(\infty) \rightarrow 0, \phi(\infty) \rightarrow 0, \chi(\infty) \rightarrow 0 \quad \text { as } \eta \rightarrow \infty .
\end{aligned}
$$

where $\operatorname{Pr}=\frac{v_{f}}{\alpha}$ is Prandtl number, $N b=\frac{\tau D_{B}\left(C_{w}-C_{\infty}\right)}{\alpha}$ is Brownian motion parameter, $N t=\frac{\tau D_{T}\left(T_{w}-T_{\infty}\right)}{\alpha T_{\infty}}$ is thermophoresis parameter, $S c=\frac{v_{f}}{D_{B}}$ is Schmidt number,
$P e=\frac{\tilde{b} W_{c}}{D_{n}}$ is Péclet number, $L b=\frac{v_{f}}{D_{N}}$ is bioconvection Lewis number, $\lambda=\frac{b}{a}$ is the ratio of the stretching rate along the $x$-direction to the $y$-direction, $p=\left(N_{1}\right)_{0} \sqrt{\frac{a}{v_{f}}}$ is velocity slip along the $x$-direction, $q=\left(N_{2}\right)_{0} \sqrt{\frac{a}{v_{f}}}$ is velocity slip along the $y$-direction, $r=\left(D_{1}\right)_{0} \sqrt{\frac{a}{v_{f}}}$ is thermal slip, $s=\left(E_{1}\right)_{0} \sqrt{\frac{a}{v_{f}}}$ is mass slip, $k=\left(F_{1}\right)_{0} \sqrt{\frac{a}{v_{f}}}$ is microorganism slip.

Important parameters of engineering interest are local skin friction factors $C_{f_{\bar{x}}}, C_{f_{\bar{v}}}$ local Nusselt numbers $N u_{\bar{x}}$, local Sherwood numbers $S h_{\bar{x}}$, local density number of motile microorganism $N n_{\bar{x}}$. These quantify the transfer rates of momentum, heat, nano-particle species and motile micro-organisms at the sheet surface. They are defined respectively as:

$$
\begin{aligned}
& C_{f_{\bar{x}}}=\frac{\tau_{z x}}{\rho_{f} \bar{u}_{w}^{2}}, C_{f_{\bar{y}}}=\frac{\tau_{z y}}{\rho_{f} \bar{v}_{w}^{2}}, N u_{\bar{x}}=\frac{(\bar{x}+\bar{y}) q_{w}}{k\left(T_{w}-T_{\infty}\right)}, \\
& S h_{\bar{x}}=\frac{(\bar{x}+\bar{y}) q_{m}}{D_{B}\left(C_{w}-C_{\infty}\right)}, N n_{\bar{x}}=\frac{(\bar{x}+\bar{y}) q_{n}}{D_{N} N_{w}},
\end{aligned}
$$

where $\tau_{\overline{z x}}$ and $\tau_{\overline{z y}}$ are the wall shear stresses; $q_{w}$ is the wall heat flux; $q_{m}$ is the wall mass flux and $q_{1}$ is, the wall motile microorganism flux and are defined by:

$$
\begin{aligned}
& \tau_{z x}=\left.\mu\left(\frac{\partial \bar{u}}{\partial \bar{z}}+\frac{\partial \bar{w}}{\partial \bar{x}}\right)\right|_{\bar{z}=0}, \quad \tau_{z y}=\left.\mu\left(\frac{\partial \bar{v}}{\partial \bar{z}}+\frac{\partial \bar{w}}{\partial \bar{y}}\right)\right|_{\bar{z}=0}, \\
& q_{w}=-\left.k \frac{\partial T}{\partial \bar{z}}\right|_{\bar{z}=0}, \quad q_{m}=-\left.D_{B} \frac{\partial C}{\partial \bar{z}}\right|_{\bar{z}=0}, q_{n}=-\left.D_{N} \frac{\partial N}{\partial \bar{z}}\right|_{\bar{z}=0} .
\end{aligned}
$$

Substitution of (8), (14) and (16) into (15), yields the following non-dimensional expressions:

$$
\begin{aligned}
& \operatorname{Re}_{\bar{x}}^{1 / 2} C_{f \bar{x}}=f^{\prime \prime}(0), \operatorname{Re}_{\bar{y}}^{1 / 2} \lambda^{3 / 2} C_{\overline{f y}}=g^{\prime \prime}(0), \\
& \operatorname{Re}_{\bar{x}}^{-1 / 2} N u_{\bar{x}}=-\theta^{\prime}(0), \quad \operatorname{Re}_{\bar{x}}^{-1 / 2} S h_{\bar{x}}=-\phi^{\prime}(0), \\
& \operatorname{Re}_{\bar{x}}^{-1 / 2} N n_{\bar{x}}=-\chi^{\prime}(0),
\end{aligned}
$$

where $\operatorname{Re}_{\bar{x}}=\frac{a(\bar{x}+\bar{y})^{n+1}}{v_{f}}$ and $\operatorname{Re}_{\bar{y}}=\frac{b(\bar{x}+\bar{y})^{n+1}}{v_{f}}$ are the local Reynolds numbers along the $x$ and $y$ directions, respectively. 


\section{NUMERICAL SOLUTION OF NONLINEAR BOUNDARY VALUE PROBLEM}

The nonlinear coupled ordinary differential equation system defined by (9)-(13) with boundary conditions (14) is solved via a BVP4C numerical method available in the symbolic code, MATLAB. The velocity components along the $x$ and $y$ directions, temperature, nanoparticle concentration and microorganism density number profiles are computed for different values of the governing parameters. The value of parameters used range between $n \geq 1,0 \leq N b, N t \leq 0.5$, and $0<P e, S c, L b \leq 5$. To verify our numerical results, we have compared our results with those reported by Khan et al. (2015b) in Table 1. Based on the accuracy of the present results, we found that the results are in very good agreement. We observed that the results obtained via BVP4C are found to be in very good agreement with the Runge-Kutta- Fehlberg quadrature, as documented in Table 2. For the validation of the BVP4C numerical procedure, the results for $-\theta^{\prime}(0)$, are compared with a Runge-Kutta-Fehlberg shooting algorithm. Further details of these numerical techniques are available in Hunt et al. (2014).

Confidence in the present BVP4C computational method is therefore high. We further note that in Table 1, the parameter $\lambda=\frac{b}{a}$ represents the $x$-direction stretching rate to the $y$-direction stretching rate. For $\lambda=1$ both $x$ and $y$ direction stretching rates are equal i.e. the sheet is stretched bi-axially at the same rate. For $\lambda=0.5$ the $y$-direction stretching rate is double that of the $x$-direction stretching rate i.e. this corresponds to unequal bi-axial stretching. When $\lambda$ is increased and all other parameters remain fixed, the heat transfer rate is significantly decreased which agrees with the findings of Wang (2015). The prescription of $n=3$ in Table 1 also implies nonlinear stretching of the sheet in both directions ( $n=1$ corresponds to the linear stretching case).

\section{NUMERICAL RESULTS AND DISCUSSION}

Selected computations have been visualized in Figures 2-10. These consider principally the influence of slip parameters and biaxial stretching rates on the transport phenomena, although certain other parameters e.g. nanoscale parameters and bioconvection Lewis number are also addressed.

Figure 2(a) and 2(b) shows the variations in horizontal and vertical components of velocity with an increase velocity slip, $p$. An increase in $p$ generates a decrease in $x$-component velocity whereas it enhances the $y$-component velocity. Momentum diffusion rates are significantly affected by the velocity slip which leads to an acceleration in the $y$-component and a deceleration in the $x$-component. A similar observation has been made by Wang $(2015,2011)$. Figure 2(c) and 2(d) indicates the temperature profile and nanoparticle volume fraction

TABLE 1. Comparison results for $f^{\prime \prime}(0)$ and $g^{\prime \prime}(0)$ for different values of $n$ and $\lambda$ at $P r=N b=N t=S c=P e=L b=\lambda=p=q=r=s=k=0$.

\begin{tabular}{cccccc}
\hline \multirow{2}{*}{$n$} & \multicolumn{2}{c}{$f^{\prime \prime}(0)$} & \multicolumn{2}{c}{$g^{\prime \prime}(0)$} \\
\cline { 2 - 5 } & & $\begin{array}{c}\text { Khan et al. } \\
(2015 b) \\
(\text { RKF45) }\end{array}$ & $\begin{array}{c}\text { Present } \\
\text { (BVP4C) }\end{array}$ & $\begin{array}{c}\text { Khan et al. } \\
(2015 b) \\
(\text { RKF45) }\end{array}$ & $\begin{array}{c}\text { Present } \\
(\text { BVP4C) }\end{array}$ \\
\hline 1 & 0 & -1 & -1.001396 & 0 & 0 \\
& 0.5 & -1.223745 & -1.225266 & -0.612372 & -0.612633 \\
& 1 & -1.414214 & -1.414441 & -1.414214 & -1.414441 \\
\hline 3 & 0 & -1.624356 & -1.624549 & 0 & 0 \\
& 0.5 & -1.989422 & -1.989473 & -0.994711 & -0.994736 \\
& 1 & -2.297186 & -2.297203 & -2.297186 & -2.297203 \\
\hline
\end{tabular}

TABLE 2. Heat transfer rates (wall temperature gradient $-\theta^{\prime}(0)$ for $N b=N t=10^{-5}$ for various parameter values with RKF45 and BVP4C numerical methods

\begin{tabular}{cccccc}
\hline \multirow{2}{*}{$n$} & $\lambda$ & $S c$ & $P r$ & \multicolumn{2}{c}{$-\theta^{\prime}(0)$} \\
\cline { 2 - 5 } & & & & RKF45 & BVP4C \\
\hline 3 & 0.5 & 3 & 7 & 1.705070 & 1.705074 \\
& & 5 & & 1.473561 & 1.473558 \\
& 1 & 10 & 13 & 1.227795 & 1.227789 \\
\cline { 2 - 5 } & 10 & 25 & 1.417734 & 1.417734 \\
& & & 2.327196 & 2.327196 \\
& & & 3.908586 & 3.908586 \\
& & 100 & 6.621042 & 6.621042 \\
& & & 10.832949 & 10.832951 \\
\hline
\end{tabular}



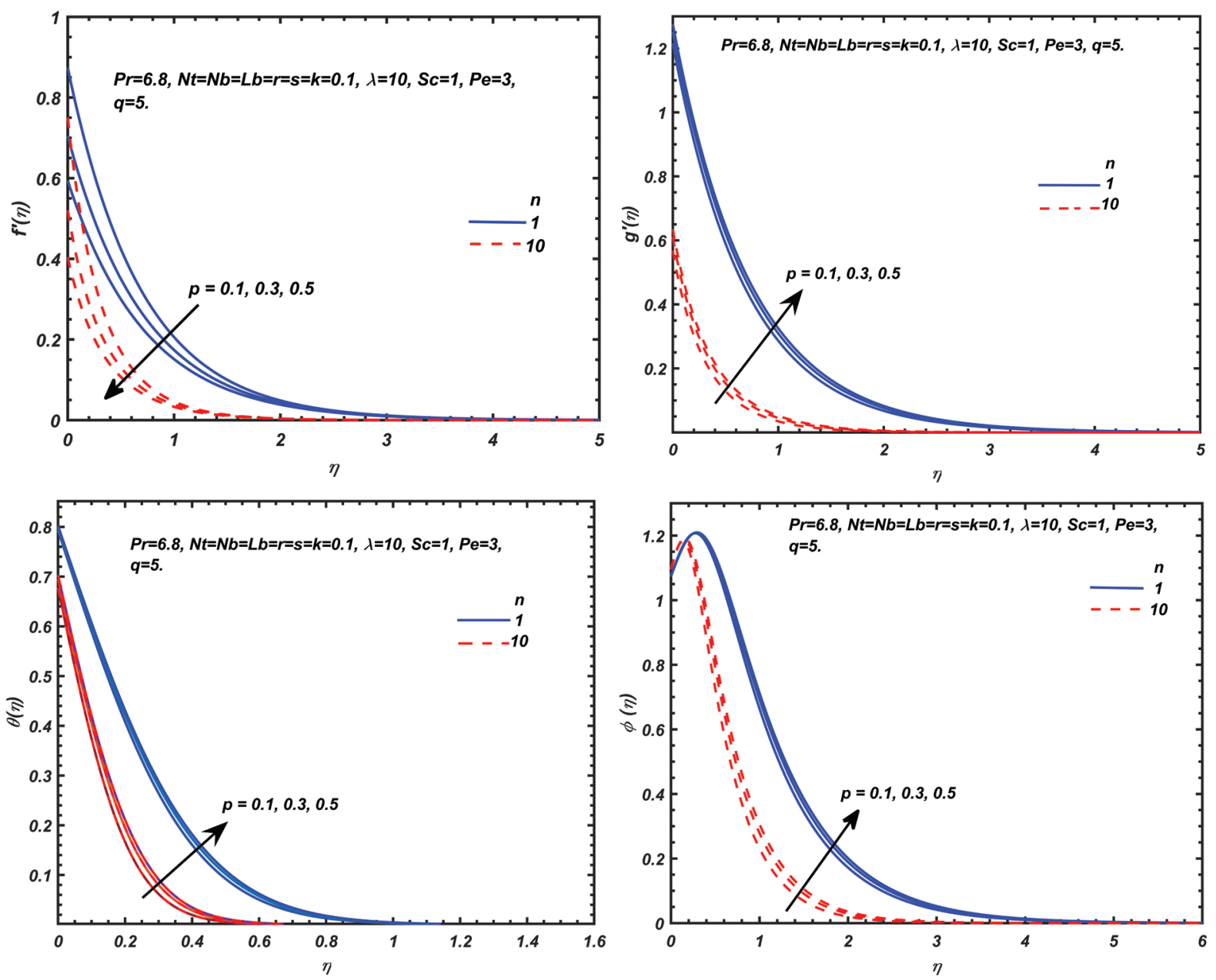

FIGURE 2. Influence of $x$-direction slip $p$ on the dimensionless (a) $x$-component velocity, (b) $y$-component velocity, (c) temperature and (d) nanoparticle volume fraction

profile increase with an increasing of $p$. Greater momentum slip at the wall serves to heat the boundary layer and increases thermal boundary layer thickness. Similarly, increase in nanoparticle volume fraction profile implies that slip at the sheet surface encourages species diffusion of nanoparticles and enhances the nano-particle concentration boundary layer thickness. In all these plots the case for $n=$ 1 (linear biaxial stretching sheet) always attains magnitudes of the respective variable which are greater than the $n=$ 10 case (nonlinear stretching biaxial sheet).

Figure 3 displays the influence of Brownian motion $(\mathrm{Nb})$ and thermophoresis parameter $(\mathrm{Nt})$ on the nanoparticle volume fraction. The impact of Brownian motion is strongly related to the size of nanoparticles. Increasing values of $\mathrm{Nt}$ indicate a stronger thermophoretic force (due to the temperature gradient) which displaces the nano-particles from the hot sheet to the quiescent fluid thereby increasing the nanoparticle volume fraction boundary layer. Interestingly, the increase in nanoparticle volume fraction with $\mathrm{Nt}$ reduces when the $\mathrm{Nb}$ effect intensifies (when $\mathrm{Nb}$ changes from 0.1 to 0.3 since larger $\mathrm{Nb}$ values correspond to smaller sized nano-particles).

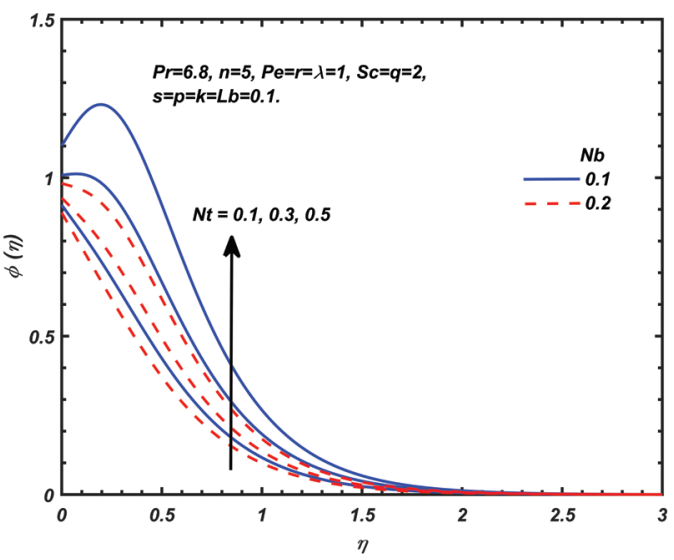

FIGURE 3. Effect of Brownian motion $(\mathrm{Nb})$ and thermophoresis parameter $(\mathrm{Nt})$ on the dimensionless (a) nanoparticle volume fraction

Increasing $N b$ reduces the wall slope of the concentration nanoparticle volume fraction and also eliminates the near-wall overshoot associated with lower $N b$ values. For smaller $\mathrm{Nb}$, the nano-particle volume fraction profiles become steeper when $N t$ is increased whereas the opposite 
trend is apparent with a stronger $N b . N b$ represents the random motion of small colloidal particles suspended in a fluid, caused by the collision of the fluid molecules with the particles (Khan et al. 2015b). $N b$ magnitudes as elaborated earlier are associated with the size of suspended nanoparticles which clearly exert a substantial influence on transport phenomena in the regime.

Figure 4(a) and 4(b) presents the effects of stretching rate ratio $\lambda$ and $y$-direction velocity slip $q$ on the dimensionless $x$-component velocity and $y$-components velocity. An increment in $\lambda$ and $q$ leads to decrease in the $x$-component velocity. However, increasing $\lambda$ and $q$ exert the opposite influence on $y$-component velocity i.e. they induce a strong acceleration. Figure 4(c)-4(e) depicts the response in dimensionless temperature, nanoparticle volume fraction and microorganism density with various values of $\lambda$ and $q$. Evidently, temperature is reduced with an increase in stretching ratio, $\lambda$, whereas it is markedly increased with an increase in $y$-direction slip parameter. As stretching rate ratio is increased from 0.5 through 0.7 to 1 (equal stretching in both $x$ - and $y$-directions) greater quantities of colder nanofluid are entrained near the
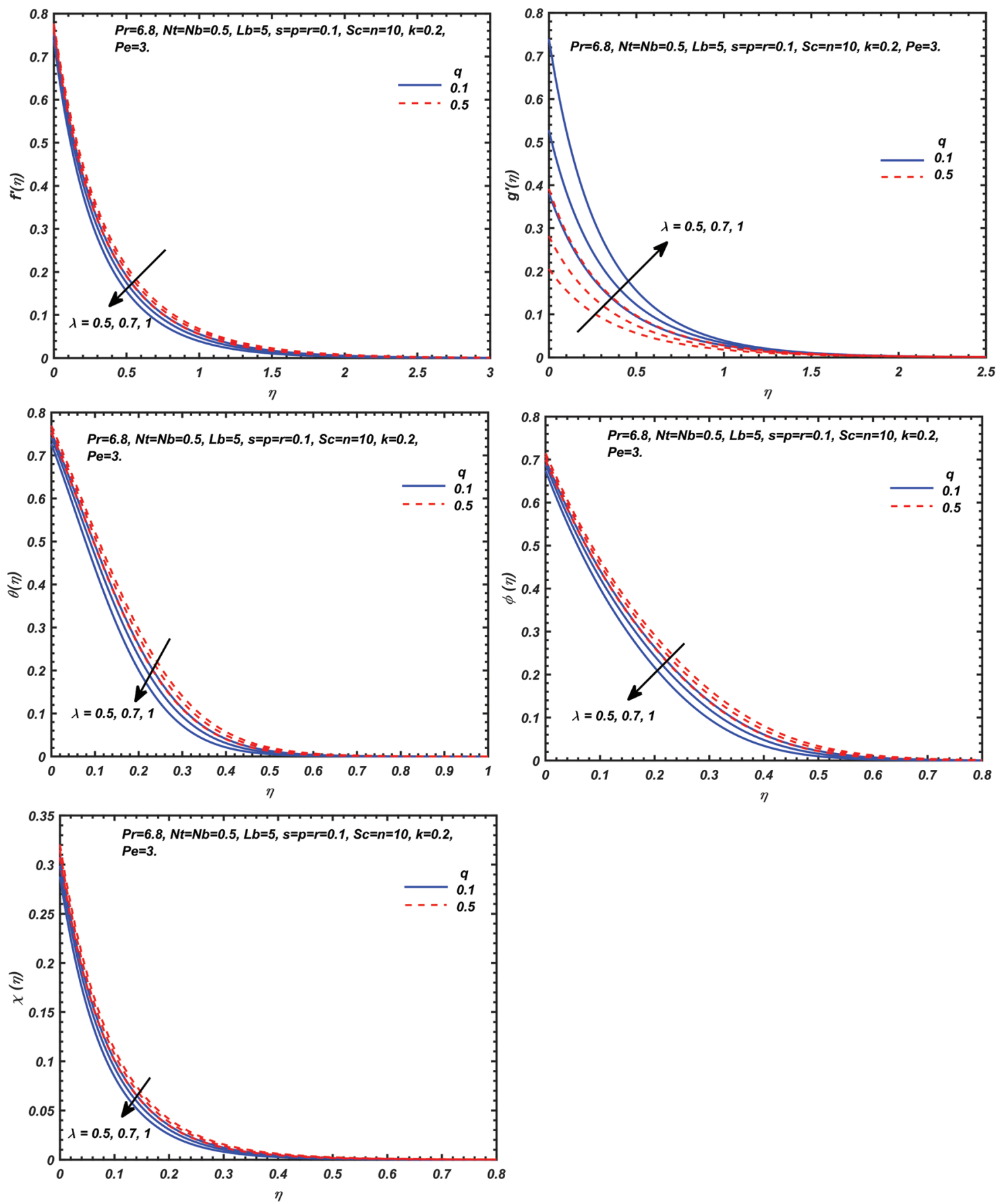

FIGURE 4. Effect of y-direction slip $(q)$ and stretching rate ratio $(\lambda)$ on dimensionless (a) $x$-component velocity, (b) $y$-component velocity, (c) temperature, (d) nanoparticle volume fraction and (e) micro-organism density number 
stretching sheet which leads to a cooling effect and an associated depletion in thermal boundary layer thickness. A similar response is computed for the nanoparticle volume fraction and micro-organism density number. Both are reduced with greater stretching rate ratio and enhanced with greater $y$-direction slip effect. Nanoparticle concentration boundary layer thickness and motile micro-organism boundary layer thickness are therefore both enhanced with greater $y$-direction slip whereas they are decreased when the $y$-direction and $x$-direction stretching rates approach each other i.e. as $\lambda$ increases towards unity.

Figure 5(a) and 5(b) illustrates the influence of thermal slip $(r)$ and nano-particle mass slip $(s)$ on temperature and nanoparticle volume fraction. In all cases, increasing thermal slip induces a significant depletion in magnitudes. Both temperature (Figure 5(a)) and nanoparticle volume fraction (Figure 5(b)) are also decreased with greater mass slip parameter. Effectively thermal boundary layer thickness and nano-particle concentration boundary layer thickness are significantly decreased with stronger thermal slip. However, while greater mass slip also reduces the thermal and nano-particle boundary layer thicknesses. Both thermal and mass slip therefore impact considerably on the diffusive phenomena in the regime.

Figure 6 presents the impact of bioconvection Péclet number $(\mathrm{Pe})$ on the motile microorganism density number, $\chi(\eta)$. Higher $P e$ signifies lower advection compared to diffusion and thus results in lower values of $\chi(\eta)$ i.e. the concentration of motile micro-organisms is depleted. It should also be noted that, as $P e$ decreases and approaches zero, $\chi(\eta)$ also will tend to zero. For $P e>1$, swimming motions will dominate species diffusivity of micro-organisms and this will lead to a reduction in $\chi(\eta)$. The converse behaviour would arise for $P e<1$. Motile micro-organism boundary layer thickness is substantially suppressed with greater bioconvection Péclet number $(\mathrm{Pe})$. With increasing micro-organism slip $(k)$, there is also a tangible reduction in motile micro-organism number
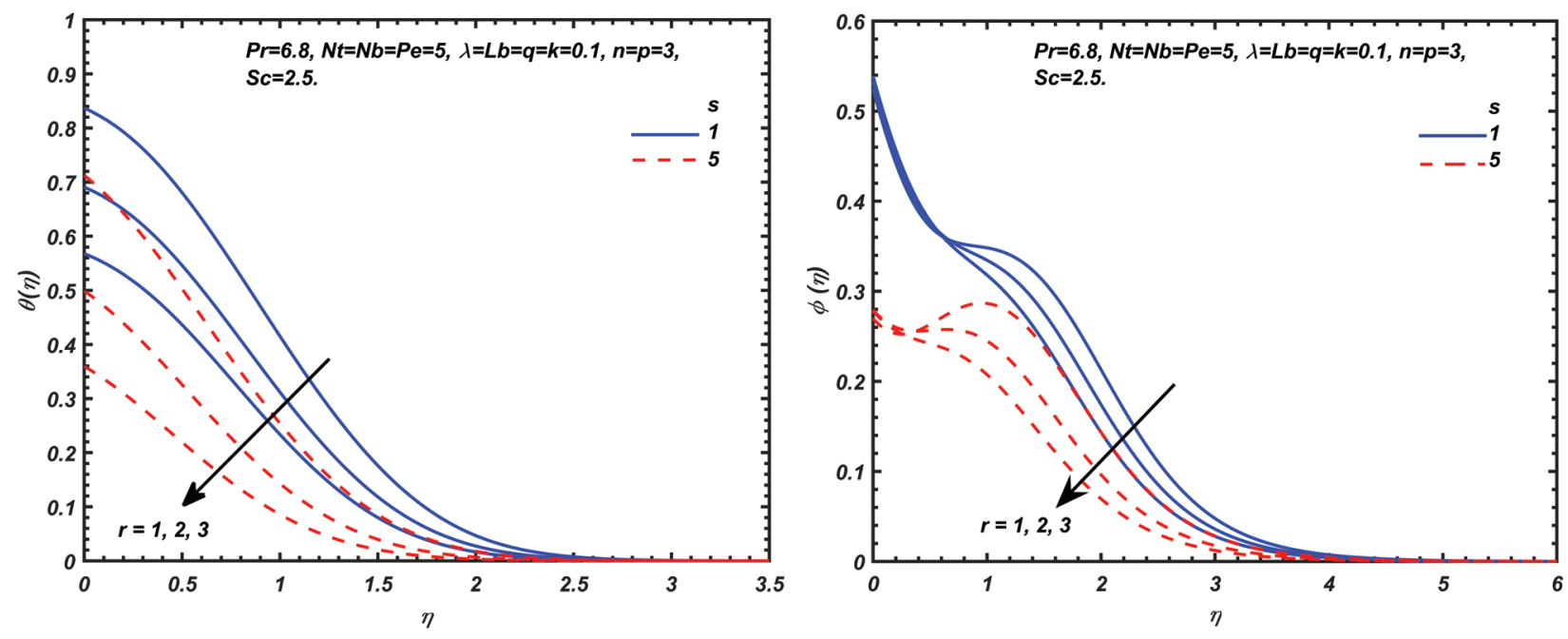

FIGURE 5. Effect of thermal slip $(r)$ and mass slip $(s)$ on the dimensionless (a) temperature, and (b) nanoparticle volume fraction

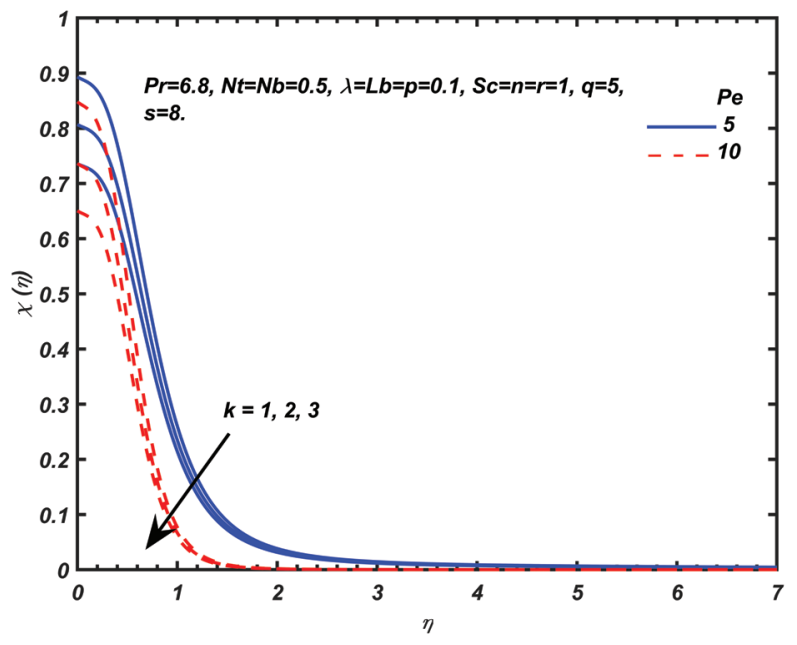

FIGURE 6. Effect of $P e$ and $k$ on the dimensionless micro-organism density number 


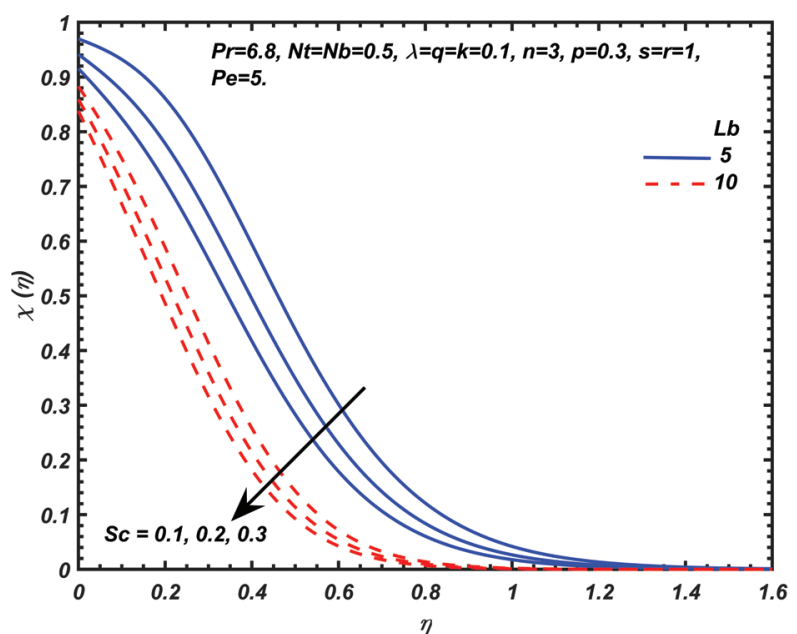

FIGURE 7. Effect of $S c$ and $L b$ on the dimensionless microorganism density number

density i.e. concentration of gyrotactic micro-organisms is strongly reduced. This effect is sustained throughout the boundary layer regime.

Figure 7 depicts the response in motile microorganism density number with Schmidt number $(S c)$ and bioconvection Lewis number $(L b)$. Schmidt number represents the ratio of momentum diffusion rate (i.e. kinematic viscosity, $v_{f}$ ) to nano-particle species diffusion rate $\left(D_{\mathrm{B}}\right)$. This parameter therefore relates to the species diffusion of nano-particles in the regime. The bioconvection Lewis number however expresses the relative rate of momentum diffusion to micro-organism species diffusion. As both parameters increase the net effect is to depress the magnitudes of motile micro-organism density number, and therefore to decrease motile micro-organism boundary layer thickness. The micro-organisms are self-propelled whereas the nano-particles are not. The influence of bioconvection Lewis number is direct as it features in the micro-organism species conservation boundary layer equation i.e. (13) in the term $\frac{n+1}{2} L b(f+g) \chi^{\prime}$. However, the influence of Schmidt number is indirectly experienced by the micro-organism field via coupling to the nanoparticle conservation (12) i.e. via the term $\frac{n+1}{2} S c(f+g) \phi^{\prime}$. Even with relatively small values of Schmidt number a strong effect is induced on the micro-organism field indicating that micro-organism diffusion is sensitive to the species diffusivity of nano-particles in addition to the species diffusivity of the micro-organisms themselves. Asymptotically smooth profiles are computed for all combinations of $L b$ and $S c$, confirming that an adequately large infinity boundary condition is imposed in the BVP4C numerical code. Indeed, in all other plots (i.e. Figures 2-6) where the transformed coordinate $\eta$ is the abscissa, smooth profiles are consistently achieved in the free stream.

Figure 8 exhibits the variations of the skin friction coefficient, $f^{\prime \prime}(0)$ with respect to $y$-direction hydrodynamic

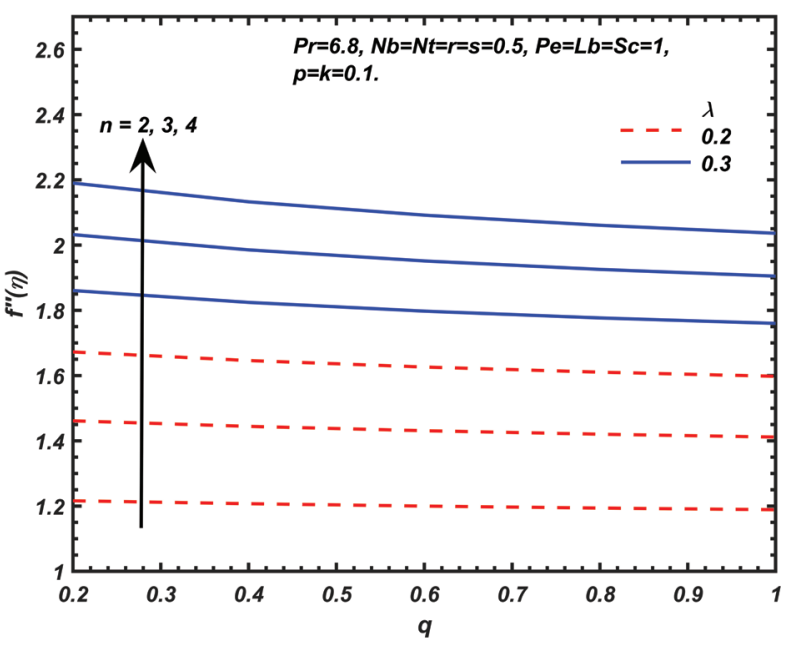

FIGURE 8 . Skin friction coefficient $f$ " $(0)$ versus $q$ and $\lambda$ for different values of $n$.

(velocity) slip, $q$ and stretching rates ratio, $\lambda$ for different values of stretching power-law parameter $(n)$. Clearly, the $x$-direction skin friction (i.e. non-dimensional shear stress at the surface) is weakly decreased with greater values of $y$-direction hydrodynamic slip. The dominant influence of the $q$ parameter is on the $y$-direction velocity component $\left(g^{\prime}\right)$ as expressed in the wall boundary condition. The secondary ( $y$-direction) velocity field is influenced and indirectly via coupling with the primary ( $x$-direction) velocity field $\left(f^{\prime}\right)$ a less pronounced effect is transmitted to the $x$-direction shear stress. A much more prominent influence is exerted by increasing the stretching rate ratio $(\lambda)$. The $x$-direction skin friction is noticeably elevated with a relatively weak increase in $\lambda$, even with small magnitudes of $\lambda$. With greater nonlinearity of the stretching sheet i.e. higher values of $n$, there is a marked increase in $\mathrm{x}$-direction skin friction component. Therefore, overall higher stretching rate and nonlinearity in stretching serve to accelerate the $x$-direction flow and will be accompanied with a decrease in momentum boundary layer thickness.

Figure 9 illustrates the variations of the local Nusselt number, $-\theta^{\prime}(0)$ i.e., wall heat transfer rate with Brownian motion parameter $(\mathrm{Nb})$ for different values of thermal slip parameter $(r)$ and thermophoresis parameter $(N t)$. Greater Brownian motion parameter values weakly decrease the local Nusselt number. Brownian motion exerts a weak influence (enhancement) on the temperature field and a much stronger influence (enhancement) on the nanoparticle volume fraction distributions. A much stronger reduction in local Nusselt number is induced however with an increase in thermophoresis parameter. This is due to the strong increase in temperatures with increasing $N t$ values. This is caused by encouraged transport of thermal energy into the body of the nanofluids bioconvection regime away from the wall (sheet) and therefore, a reduction in wall heat transfer rates. A substantial decrease in local Nusselt number is also computed with greater thermal slip (jump) effect. 


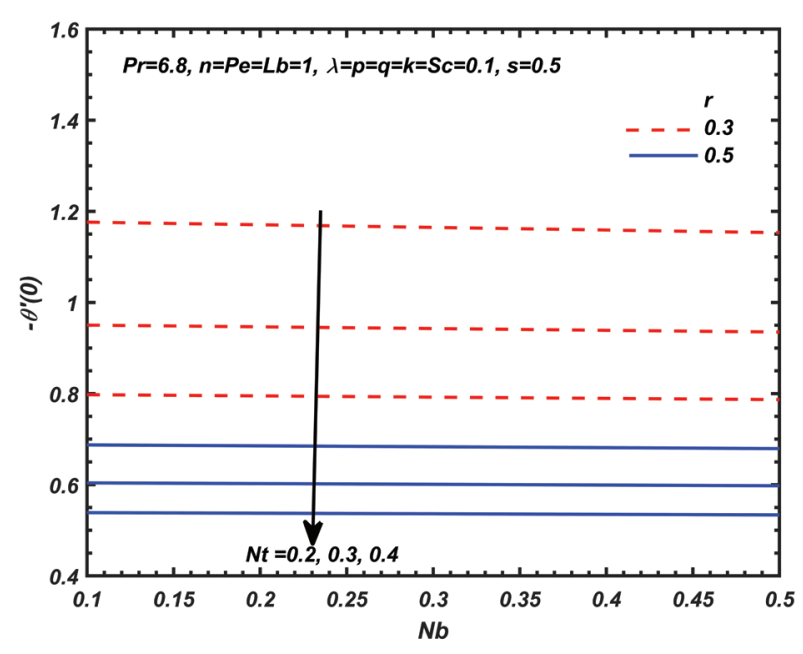

FIGURE 9. Local Nusselt number, $-\theta^{\prime}(0)$ versus $N b$ and $r$ for a different value of $N t$.

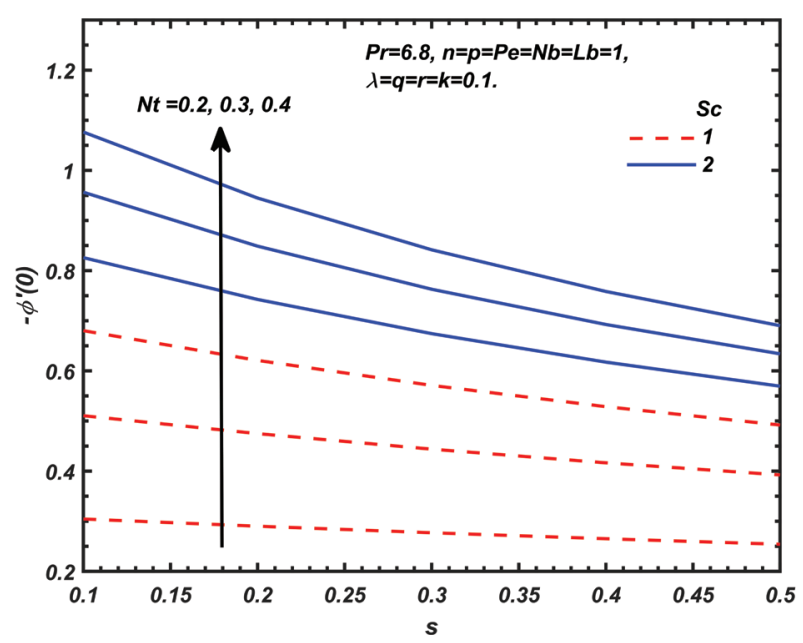

FIGURE 10. Local Sherwood number, $-\phi^{\prime}(0)$ versus $S c$ and $s$ for a different value of $N t$.

Figure 10 presents the allocations for local mass transfer rate, $-\phi^{\prime}(0)$ versus Schmidt number, $S c$ and mass slip, $s$ with different values of thermophoresis parameter $(N t)$. The graph discloses that $-\phi^{\prime}(0)$ upsurges with Schmidt number and thermophoresis parameter whereas it is degraded noticeably with profounder mass slip effect. Slip basically retards the fluid motion which finally shows a decrease in net molecular movement. Consequently, less molecular movement decreases both temperature and mass fraction fields. Since if the thermal slip parameter can control the temperature inside the flow then it is quite possible the mass transport phenomenon can be controlled by the concentration slip parameter. Thus, we have also analysed the combined effects of velocity, thermal and concentration slip parameters on the flow. Quite interestingly we have found that the effects of concentration slip parameter are quite like those of thermal slip parameter. Schmidt number $S c$ is the ratio of dynamic viscosity and Brownian diffusion coefficient.
Schmidt number is dependent on the Brownian diffusion coefficient. Therefore, higher values of Schmidt number lead to the lower Brownian diffusion coefficient. As a result, this shows a weaker nanoparticle concentration but increases the local Sherwood number. The non-inclusion of slip effects will clearly lead to erroneous computations which will diverge from results of relevance to practical applications.

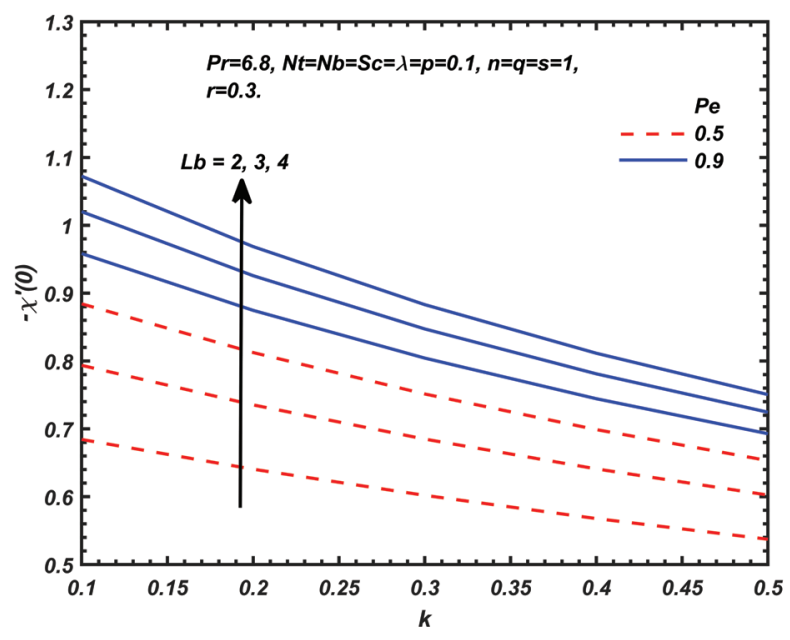

FIGURE 11. Local density number of motile microorganism, $-\chi^{\prime}(0)$, versus $k$ and $P e$ with different values of bioconvection Lewis number $(L b)$

Figure 11 presents the distributions for local microorganism mass transfer rate, $-\chi^{\prime}(0)$ versus Péclet number, $P e$ and micro-organism slip, $k$ with different values of bioconvection Lewis number, $L b$. The graph shows that $-\chi^{\prime}(0)$ increases with bioconvection Lewis number and bioconvection Péclet number whereas it is reduced considerably with greater micro-organism slip effect. The inclusion of micro-organism slip is therefore important since omission of this effect will lead to over-estimation in magnitudes of local micro-organism mass transfer rate, $-\chi^{\prime}(0)$. This implies that the adoption of no-slip conditions will produce results which deviate from real situations encountered in industrial systems.

\section{CONCLUSION}

Enhancement of mathematical model has been done for three-dimensional bioconvection flow of nanofluids containing gyrotactic micro-organisms from a bi-axial stretching sheet with anisotropic slip, thermal jump and mass slip effects. The dual (primary and secondary) momentum, nano-particle concentration, energy and micro-organism density conservation equations have been transformed with appropriate variables and under specified boundary conditions. The emerging nonlinear two-point ordinary differential boundary value problem has been solved with the BVP4C MATLAB numerical code. Validation 
of solutions has been included with an RKF shooting quadrature. A parametric study has been conducted of the influence of anisotropic slip factors, nanoscale parameters and bioconvection parameters on the momentum, heat, nano-particle and micro-organisms transport phenomena. The present computations have shown that:

The $x$-direction skin friction is weakly decreased with $y$-direction hydrodynamic slip whereas it enhanced with increasing bi-axial stretching rate ratio and power-law index. The local Nusselt number is decreased weakly with an increment of Brownian motion whereas it is strongly reduced with greater thermal slip and thermophoresis parameters. The local motile micro-organism mass transfer rate at the sheet is decreased with increasing microorganism slip whereas it is enhanced with bioconvection Péclet number and bioconvection Lewis number. Motile micro-organism density number and micro-organisms species boundary layer thickness are both reduced with increasing Schmidt number and bioconvection Lewis number. Motile micro-organism boundary layer thickness is significantly decreased with an increase in bioconvection Péclet number andmicro-organism slip factor. Nano-particle concentration and motile microorganism density number are elevated with increasing $y$-direction slip whereas they are reduced with increasing stretching rate ratio. Temperature, nanoparticle volume fraction and motile micro-organism density number are decreased with greater thermal slip. Temperature and nanoparticle volume fraction (concentration) are depressed with increasing nano-particle mass slip parameter, whereas motile micro-organism density is increased substantially. Temperature and nanoparticle volume fraction magnitudes are enhanced with increasing $\mathrm{x}$-direction slip.

The current analysis has presented some insight into anisotropic slip and bi-axial stretching in nanofluids bioconvection boundary layer flow. The computations may be relevant to materials processing of nano-bioconvection systems and nano-bio-fuel cells. Attention has been confined however to Newtonian viscous base fluids and shape effects of nano-particles have been ignored. Future studies will aim to examine nanoparticle shape effects and non-Newtonian base fluid models (Hassan et al. 2017; Majeed et al. 2018; Soid et al. 2018; Zokri et al. 2018).

\section{ACKNOWLEDGEMENTS}

The authors acknowledge financial support from Universiti Sains Malaysia, RU Grant 1001/PMATHS/8011013. The authors declare no conflict of interest.

\section{REFERENCES}

Abdul Latiff, N.A., Uddin, M.J., Bég, O.A. \& Ismail, A.I.M. 2016. Unsteady forced bioconvection slip flow of a micropolar nanofluid from a stretching/shrinking sheet. Proceedings of the Institution of Mechanical Engineers, Part N: Journal of Nanomaterials, Nanoengineering and Nanosystems 230(4): 177-187.
Akbar, N.S., Tripathi, D., Bég, O.A. \& Khan, Z.H. 2016. MHD dissipative flow and heat transfer of Casson fluids due to metachronal wave propulsion of beating cilia with thermal and velocity slip effects under an oblique magnetic field. Acta Astronautica 128: 1-12.

Akbarzadeh, M., Rashidi, S., Karimi, N. \& Ellahi, R. 2018. Convection of heat and thermodynamic irreversibilities in two-phase, turbulent nanofluid flows in solar heaters by corrugated absorber plates. Advanced Powder Technology 29(9): 2243-2254.

Alamri, Sultan, Z., Ellahi, R., Shehzad, N. \& Zeeshan, A. 2019. Convective radiative plane Poiseuille flow of nanofluid through porous medium with slip: An application of Stefan blowing. Journal of Molecular Liquids 273: 292-304.

Amirsom, N.A., Uddin, M.J. \& Ismail, A.I.M. 2016. Three dimensional stagnation point flow of bionanofluid with variable transport properties. Alexandria Engineering Journal 55(3): 1983-1993.

Aziz, R.C., Hashim, I. \& Abbasbandy, S. 2018. Flow and heat transfer in a nanofluid thin film over an unsteady stretching sheet. Sains Malaysiana 47(7): 1599-1605.

Bég, O.A., Md Basir, M.F., Uddin, M.J. \& Ismail, A.I.M. 2017. Numerical study of slip effects on unsteady asymmetric bioconvective nanofluid flow in a porous microchannel with an expanding/contracting upper wall using buongiorno's model. Journal of Mechanics in Medicine and Biology 17(03): 1750059.

Begum, N., Siddiqa, S. \& Hossain, M.A. 2017. Nanofluid bioconvection with variable thermophysical properties. Journal of Molecular Liquids 231: 325-332.

Buongiorno, J. 2006. Convective transport in nanofluids. Journal of Heat Transfer 128(3): 240-250.

Chamkha, A.J. \& Aly, A.M. 2010. MHD free convection flow of a nanofluid past a vertical plate in the presence of heat generation or absorption effects. Chemical Engineering Communications 198(3): 425-441.

Chamkha, A.J., Modather Mohamed, M.M.E.L., Saber, K \& Rashad, A.M. 2012a. Radiative effects on boundarylayer flow of a nanofluid on a continuously moving or fixed permeable surface. Recent Patents on Mechanical Engineering 5(3): 176-183.

Chamkha, A.J., Abbasbandy, S., Rashad, A.M. \& Vajravelu, K. 2012b. Radiation effects on mixed convection over a wedge embedded in a porous medium filled with a nanofluid. Transport in Porous Media 91(1): 261-279.

Chen, C.Y., Chen, Q.D. \& Li, W.L. 2013. Characteristics of journal bearings with anisotropic slip. Tribology International 61: 144-155.

Choi, S.U. \& Eastman, J. 1995. Enhancing thermal conductivity of fluids with nanoparticles. ASME International Mechanical Engineering Congress \& Exhibition. American Society of Mechanical Engineers, San Francisco 196525: 12-17.

Hassan, M., Marin, Alsharif, M.A. \& Ellahi, R. 2018a. Convective heat transfer flow of nanofluid in a porous medium over wavy surface. Physics Letters A 382(38): 2749-2753.

Hassan, M., Mari, M., Ellahi, R.\& Alamri, S.Z. 2018b.Exploration of convective heat transfer and flow characteristics synthesis by $\mathrm{Cu}-\mathrm{Ag} /$ water hybrid-nanofluids. Heat Transfer Research 49(18): 1837-1848.

Hassan, M., Zeeshan, A., Majeed, A. \& Ellahi, R. 2017. Particle shape effects on ferrofuids flow and heat transfer under influence of low oscillating magnetic field. Journal of Magnetism and Magnetic Materials 443: 36-44. 
Hunt, B.R., Lipsman, R.L. \& Rosenberg, J.M. 2014. A Guide to MATLAB®: For Beginners and Experienced Users. 3rd ed. Cambridge: Cambridge University Press.

Hussain,F., Ellahi, R. \& Zeeshan,A. 2018. Mathematical models of electro-magnetohydrodynamic multiphase flows synthesis with nano-sized hafnium particles. Applied Sciences 8(2): 275.

Jamaludin, A., Nazar, R. \& Pop, I. 2018. Ingham problem for mixed convection flow of a nanofluid over a moving vertical plate with suction and injection effects. Sains Malaysiana 47(9): 2213-2221

Jao, H., Chang, K., Chu, L.M. \& Li, W. 2016. A lubrication theory for anisotropic slips and flow rheology. Tribology Transactions 59(2): 252-266.

Khan, J.A., Mustafa, M., Hayat, T., Sheikholeslami, M. \& Alsaedi, A. 2015a. Three-dimensional flow of nanofluid induced by an exponentially stretching sheet: An application to solar energy. PLOS ONE 10(3): e0116603.

Khan, J.A., Mustafa, M., Hayat, T. \& Alsaedi, A. 2015b. Threedimensional flow of nanofluid over a non-linearly stretching sheet: An application to solar energy. International Journal of Heat and Mass Transfer 86: 158-164.

Khan, W.A., Uddin, M.J. \& Ismail, A.I.M. 2013. Free convection of non-Newtonian nanofluids in porous media with gyrotactic microorganisms. Transport in Porous Media 97(2): 241-252.

Kuznetsov, A.V. 2012. Nanofluid bioconvection: Interaction of microorganisms oxytactic upswimming, nanoparticle distribution, and heating/cooling from below. Theoretical and Computational Fluid Dynamics 26 (1-4): 291-310.

Kuznetsov, A.V. \& Avramenko, A.A. 2004. Effect of small particles on this stability of bioconvection in a suspension of gyrotactic microorganisms in a layer of finite depth. International Communications in Heat and Mass Transfer 31(1): 1-10.

Liu,I. \& Andersson, H.I. 2008. Heat transfer over a bidirectional stretching sheet with variable thermal conditions. International Journal of Heat and Mass Transfer 51(15-16): 4018-4024.

Liu, I., Wang, H. \& Peng, Y. 2013. Flow and heat transfer for three-dimensional flow over an exponentially stretching surface. Chemical Engineering Communications 200(2): 253-268.

Mahat, R., Rawi, N.A., Mohd Kasim, A.R. \& Shafie, S. 2018. Mixed convection flow of viscoelastic nanofluid past a horizontal circular cylinder with viscous dissipation. Sains Malaysiana 47(7): 1617-1623.

Majeed, A., Zeeshan, A., Alamri, S.Z. \& Ellahi, R. 2018. Heat transfer analysis in ferromagnetic viscoelastic fluid flow over a stretching sheet with suction. Neural Computing and Applications 30(6): 1947-1955.

Maqbool, K., Bég, O.A., Sohail, A. \& Idreesa, S. 2016. Analytical solutions for wall slip effects on magnetohydrodynamic oscillatory rotating plate and channel flows in porous media using a fractional Burgers viscoelastic model. The European Physical Journal Plus 131(5): 140.

Md Basir, M.F., Uddin, M.J., Ismail, A.I.M. \& Bég, O.A. 2016. Nanofluid slip flow over a stretching cylinder with Schmidt and Péclet number effects. AIP Advances 6(5): 055316.

Michaelides, E.E. 2015. Brownian movement and thermophoresis of nanoparticles in liquids. International Journal of Heat and Mass Transfer 81: 179-187.

Mustafa, M., Mushtaq, A., Hayat, T. \& Alsaedi, A. 2015. Radiation effects in three-dimensional flow over a bi- directional exponentially stretching sheet. Journal of the Taiwan Institute of Chemical Engineers 47: 43-49.

Prasad, V.R., Rao, A.S., Reddy, N.B., Vasu, B. \& Bég, O.A. 2013. Modelling laminar transport phenomena in a Casson rheological fluid from a horizontal circular cylinder with partial slip. Proceedings of the Institution of Mechanical Engineers, Part E: Journal of Process Mechanical Engineering 227(4): 309-326.

Raees, A., Raees-ul-Haq, M., Xu, H. \& Sun, Q. 2016. Threedimensional stagnation flow of a nanofluid containing both nanoparticles and microorganisms on a moving surface with anisotropic slip. Applied Mathematical Modelling 40(5-6): 4136-4150.

Rao, A.S., Prasad, V.R., Harshavalli, K. \& Beg, O.A. 2016 Thermal radiation effects on non-Newtonian fluid in a variable porosity regime with partial slip. Journal of Porous Media 19(4): 313-329.

Rashad, A.M. 2017. Impact of anisotropic slip on transient three dimensional MHD flow of ferrofluid over an inclined radiate stretching surface. Journal of the Egyptian Mathematical Society 25(2): 230-237.

Rashidi, S., Akar, S., Bovand, M. \& Ellahi, R. 2018. Volume of fluid model to simulate the nanofluid flow and entropy generation in a single slope solar still. Renewable Energy 115: 400-410

Saidur, R., Leong, K.Y. \& Mohammad, H.A. 2011 . A review on applications and challenges of nanofluids. Renewable and Sustainable Energy Reviews 15(3): 1646-1668.

Shehzad, N.,Zeeshan, A. \& Ellahi, R. 2018. Electroosmotic flow of MHD power law Al2O3-PVC nanouid in a horizontal channel: Couette-Poiseuille flow model. Communications in Theoretical Physics 69(6): 655-666.

Siddiqa, S., Begum, N., Saleem, S., Hossain, M.A. \& Gorla R.S.R. 2016. Numerical solutions of nanofluid bioconvection due to gyrotactic microorganisms along a vertical wavy cone. International Journal of Heat and Mass Transfer 101: 608-613.

Soid, S.K., Ishak, A. \& Pop, I. 2018. MHD stagnation-point flow over a stretching/shrinking sheet in a Micropolar fluid with a slip boundary. Sains Malaysiana 47(11): 2907-2916.

Sokolov, A., Goldstein, R.E., Feldchtein, F.I. \& Aranson, I.S. 2009. Enhanced mixing and spatial instability in concentrated bacterial suspensions. Physical Review E 80(3): 031903.

Tripathi, D., Bég, O.A. \& Curiel-Sosa, J.L. 2014. Homotopy semi-numerical simulation of peristaltic flow of generalised Oldroyd-B fluids with slip effects. Computer Methods in Biomechanics and Biomedical Engineering 17(4): 433-442.

Tsai, T.H., Liou, D.S., Kuo, L.S. \& Chen, P.H. 2009. Rapid mixing between ferro-nanofluid and water in a semi-active Y-type micromixer. Sensors and Actuators A: Physical 153(2): 267-273

Turkyilmazoglu, M. 2015. Exact multiple solutions for the slip flow and heat transfer in a converging channel. Journal of Heat Transfer 137(10): 101301.

Uddin, M.J., Khan, W.A., Ismail, A.I.M. \& Bég, O.A. 2016. Computational study of three-dimensional stagnation point nanofluid bioconvection flow on a moving surface with anisotropic slip and thermal jump effect. Journal of Heat Transfer 138(10): 104502.

Uddin, M.J., Bég, O.A. \& Ismail, A.I.M. 2015. Radiative convective nanofluid flow past a stretching/shrinking sheet with slip effects. Journal of Thermophysics and Heat Transfer 29(3): 513-523. 
Uddin, M.J., Khan, W.A. \& Ismail, A.I.M. 2013. Effect of dissipation on free convective flow of a non-Newtonian nanofluid in a porous medium with gyrotactic microorganisms. Proceedings of the Institution of Mechanical Engineers, Part $N$ : Journal of Nanoengineering and Nanosystems 227(1): 11-18.

Wang, C.Y. 2015. Uniform flow over a bi-axial stretching surface. Journal of Fluids Engineering 137(8): 084502.

Wang, C.Y. 2013. Stagnation flow on a plate with anisotropic slip. European Journal of Mechanics-B/Fluids 38: 73-77.

Wang, C.Y. 2011. A fluid film sprayed on a three-dimensional stretching/shrinking sheet. Fluid Dynamics Research 43(5): 055501 .

Webb, R.L. \& Kim, N. 2004. Principles Enhanced Heat Trans. New York: Garland Science.

Xu, H. \& Pop, I. 2012. Fully developed mixed convection flow in a vertical channel filled with nanofluids. International Communications in Heat and Mass Transfer 39(8): 10861092.

Zeeshan,A., Ijaz, N.,Abbas, T. \& Ellahi, R. 2018. The sustainable characteristic of bio-bi-phase flow of peristaltic transport of MHD Jeffrey fluid in the human body. Sustainability 10(8): 2671.

Zokri, S.M., Arifin, N.S., Mohamed, M.K.A., Kasim, A.R.M., Mohammad, N.F. \& Salleh, M.Z. 2018. Mathematical model of mixed convection boundary layer flow over a horizontal circular cylinder filled in a Jeffrey fluid with viscous dissipation effect. Sains Malaysiana 47(7): 1607-1615.
Nur Ardiana Amirsom, M.J. Uddin, Md. Faisal Md Basir* \& A.I.M Ismail

School of Mathematics Sciences

Universiti Sains Malaysia

11800 Pulau Pinang

Malaysia

M.J. Uddin

Department of Mathematics

American International University- Bangladesh

Kuratoli, Dhaka, 1229

Bangladesh

O. Anwar Bég \& Ali Kadir

Aeronautical and Mechanical Engineering Department

School of Computing, Science and Engineering

Newton Building, University of Salford, M54WT

United Kingdom

*Corresponding author; email: mfaisalmbasir@usm.my

Received: 24 December 2018

Accepted: 16 March 2019 